\title{
EDITORIAL
}

\section{Aseguramiento de la calidad y la investigación en las universidades ${ }^{1}$}

La investigación, se configura en la actualidad como una actividad relevante al interior del quehacer académico de las universidades alrededor del mundo, junto con la docencia y la vinculación con el medio. Sin lugar a dudas, la investigación, al ser el elemento catalizador en la generación y la difusión de nuevos conocimientos, resulta clave para que las instituciones universitarias se desenvuelvan de la mejor forma en la actual sociedad del conocimiento.

Dicho esto, vale precisar que los objetivos fundamentales de las universidades que se dedican a la investigación no han cambiado en su esencia durante los últimos 200 años, por tanto, se sigue esperando que los académicos continúen produciendo conocimiento avanzado, por medio de la investigación, y que luego lo utilicen para enseñar, así como también para generar bienestar en la sociedad ${ }^{2}$.

Por tanto, para responder oportunamente y de la mejor forma a lo que la sociedad espera de las universidades, respecto a la generación y difusión de conocimientos, estas instituciones deben preocuparse por el desarrollo de estrategias que fortalezcan la investigación y que permitan a los académicos ser parte de estos procesos, que les permitan ser competitivos dentro de un marco tanto nacional como internacional, donde la calidad de las diferentes esferas del quehacer académico es un factor preponderante a considerar. Competitivos, en el sentido de que hoy en día gran parte de los fondos para el desarrollo de investigaciones vienen por la vía de fondos que son concursables, pues Chile en el año 2014 destinó solo 0,38\% del PIB para el gasto en Investigación y Desarrollo, muy por debajo de lo que destinan otras naciones, como Israel que para el mismo período destino el $4,11 \%$ a esas actividades relevantes.

La importancia de la investigación al interior de las universidades se puede asociar también a las evaluaciones comparativas del desempeño institucional que indirectamente se realizan, por parte de organismos públicos, donde se definen objetivos comunes y se instalan jerarquías basadas en el desempeño medido, lo que a su vez permite diferenciar a las instituciones de educación superior dentro del mercado ${ }^{3}$. Las instituciones de educación superior, por ende, estarán cada vez más sujetas a comparaciones y clasificaciones, y aquellas consideradas como las mejores en estos rankings de las universidades de investigación seguirán siendo percibidas como las mejores del mundo 4 . Las universidades, con una marcada tendencia hacia la investigación, resultan claves para el desarrollo económico y social, de una economía y sociedad sustentada en el conocimiento. Asimismo, en el mundo globalizado que impera en la actualidad, se torna posible que el impacto de los resultados de las investigaciones trascienda las fronteras de los estados nacionales.

La investigación es, por consiguiente, una actividad que es capaz de generar un atributo diferenciador entre las instituciones universitarias, puesto que sirve para definir la magnitud y la complejidad

Proyecto FONDECYT No 1171276.

2 Harland, T. (2017). The Contemporary Research University and the Contest for Deliberative Space. In Daniel, B. (Ed.). Big Data and Learning Analytics in Higher Education (pp. 73-86). Springer International Publishing.

3 Marginson, S. (2017). Global trends in higher education financing: The United Kingdom. International Journal of Educational Development. doi: 10.1016/j.ijedudev.2017.03.008

4 Salmi, J. \& Liu, N.C. (2011). Paths to a world-class university. In: Liu, N.C.; Cheng, Y. \& Wang, Q. (Eds.). Paths to a worldclass university: Lessons from practices and experiences (pp. ix-xviii). Rotterdam: Sense Publishers. 
organizacional de las universidades sirviendo, a su vez, como un insumo relevante a ser considerado por parte de las políticas públicas al momento de definir la asignación y distribución de los recursos por parte del Estado entre dichas instituciones. De igual modo, el nivel de los recursos y capacidades institucionales se ven reflejados en el grado de desarrollo que logran las universidades en el ámbito de la investigación siendo crucial el rol del cuerpo académico.

Es imperativo, por tanto, para las universidades, establecer mecanismos que resguarden no solo la calidad institucional, sino que también se incorporen dentro de sus mecanismos de aseguramiento de la calidad las distintas áreas de su quehacer, en particular la investigación, definiéndola de esta forma como una actividad central. Junto con ello, se requiere, a nivel de institución, la definición de políticas y estrategias que releven la importancia que tiene esta función dentro del quehacer académico y que sea conocido por la comunidad universitaria en su conjunto, en particular por los estudiantes, pues la investigación es un catalizador para la generación de nuevos conocimientos y para contribuir a la solución de problemas en el entorno.

Es en esta vinculación donde se genera la oportunidad que tienen los estudiantes de participar en una investigación tutorada por un académico, lo que es una ventaja distintiva de este tipo de universidades ${ }^{5}$. Este tipo de acciones va desarrollando competencias en los estudiantes que van desde la formulación de un problema de investigación, el planteamiento de objetivos, la revisión de bibliografía y la redacción de artículos científicos, solo por mencionar algunas acciones.

En consecuencia, resulta necesario fortalecer la investigación como un activo estratégico que crea valor al interior de las instituciones de educación superior. En este sentido, uno de los aspectos a destacar hace referencia al establecimiento de mecanismos de aseguramiento de la calidad para la vinculación entre la investigación y la docencia de pregrado en las universidades; aspecto fundamental si lo que se pretende es ir generando capacidades investigativas en los futuros profesionales que formarán parte de la sociedad y que contribuirán al desarrollo del país desde diversas áreas en las que son hoy en día formados.

\author{
Carmen Araneda-Guirriman \\ Escuela de Ingenieria Industrial \\ Informática y de Sistemas \\ caraneda@uta.cl
}

\author{
Liliana Pedraja-Rejas \\ Escuela de Ingeniería Industrial \\ Informática y de Sistemas \\ lpedraja@uta.cl
}

\footnotetext{
5 Brint, S. (2015). Research university spaces: The Multiple Purposes of an Undergraduate Education. Research \& Occasional Paper Series, CSHE.9.16. University of California, Berkeley.
} 